Anthropol. Sci. 104(1), 1-14, 1996

\title{
Correlation between the Morphology of the Feet and Muscle Fiber Composition in the Anterior Tibial Muscle
}

\author{
TADANAO KimURA \\ Department of Anatomy, Showa University School of Medicine, \\ 1-5-8 Hatanodai, Shinagawa-ku, Tokyo 142, Japan
}

Received July 10, 1992

\begin{abstract}
Functional differences among the shapes of the feet in mammals, i.e. plantigrade, digitigrade and unguligrade types, were investigated in terms of muscle fiber composition, in specimens of the anterior tibial muscle, obtained from 17 species of mammals. The number of muscle fibers per unit area was the largest in the digitigrade type (on the order of 990 cells), followed by the unguligrade type (on the order of 750 cells) and was the smallest in the plantigrade type (on the order of 540 cells). With respect to the muscle fiber type, red muscle fibers for slow contraction were most frequently seen in the unguligrade type, white muscle for fast contraction in the plantigrade type and intermediate muscle fiber for plastic contraction in the digitigrade type.
\end{abstract}

Key Words: mammals, anterior tibial muscle, muscle fiber type, locomotion

\section{INTRODUCTION}

The morphology of the feet in mammals can be divided into three types: the plantigrade type, in which the entire sole of the foot touches the ground as in primates including humans, rodentia, and some carnivora such as bears; digitigrade type, in which only the phalanges of the foot touch the ground and the metatarsal and tarsal bones are not in contact with the ground, as in canidae and felidae of carnivora; and unguligrade type, in which the phalanges of the foot are differentiated into the hoof, as in artiodactyla and perissodactyla (Hildebrand, 1982). Among the muscles of the leg, the anterior tibial muscle, which participates in the dorsiflexion of the ankle joints and is responsible for walking and running, was used as the sample to document three types of muscle fibers with different forms of contraction: red muscle fibers (Type 1), white muscle fibers (Type 2) and intermediate muscle fibers (Type 3) (Denny-Brown, 1929; Padykula and Herman, 1955; Ogata, 1958; Dubowitz and Pearse, 1960; Stein and Padykula, 1962; Romanul, 1964; Edgerton and Simpson, 1969; Barnard et al., 1971). In this study, the correlation between the morphology of the mammalian feet and muscle fiber composition was examined in the anterior tibial muscle from a comparative morphological point of view.

\section{MATERIALS AND METHODS}

One hundred and nineteen specimens obtained from 17 species of mammals of 
6 orders were classified according to the morphology of the feet (Table 1). Specimens of the anterior tibial muscle (about $1.5 \mathrm{~cm}$ thick) were extracted from a cross section of the venter, fixed in neutral formalin, washed with water and dehydrated. Subsequently, the specimens were embedded in $10 \%$ gelatin, frozen in liquefied carbonic acid gas, sliced to $20-25 \mu \mathrm{m}$ in thickness with a Sartrius-type microtome and immediately stained with Sudan black B (SBB) solution. According to the pigment reaction, the specimens were divided into red muscle fibers (R), intermediate muscle fibers (I) and white muscle fibers (W). Specimens from rats, rabbits, and dogs were classified into three muscle fiber type by Succinic dehydrogenase (SDH), according to the method of Nachlas et al. (1957) and correspondence with SBB was examined. In the analysis of muscle fiber types, lines toward the direction of the $\mathrm{Y}$ - and $\mathrm{X}$-axes were assumed to exist against the polarity of the muscle (Fig. 1A). Using a 100-micrometer scale attached to a microscope and the mechanical stage, the frequencies of red, intermediate and white muscle fibers were calculated at 100 points throughout the specimen, by the method shown in Fig. 1B.

\section{RESULTS}

1) Findings of the muscle fiber types

When the tissue of the anterior tibial muscle was stained with SBB (Fig. 2), red muscle fibers $(\mathrm{R})$ of small diameter with slow contraction showed a strong positive reaction to the pigment. White muscle fibers (W) of large diameter with fast contraction demonstrated no reaction to the pigment. Intermediated muscle fibers (I) of intermediate diameter with plastic contraction showed moderate pigment response. In response to Fig. 3, Type 1 fibers of small diameter (R) showed formazan with strong enzyme activity, as in the case of SBB, while Type $2(\mathrm{~W})$ fibers of large diameter were inactive. In Type 3 (I) fibers of intermediate diameter, moderate formazan formation was observed. Thus, the patterns shown by SBB and $\mathrm{SDH}$ were in agreement with each other.

\section{2) Number of muscle fibers per unit area}

The cross sectional area of the venter of the anterior tibial muscle was examined by the scanning method, and the number of muscle fibers in a unit area of $1 \mathrm{~mm}^{2}$ was determined. The frequencies of red, intermediate and white muscle fibers were calculated according to the shape of the feet and the average value for each species is presented in Table 2. Among the 17 species of 6 orders, the lowest number of muscle fibers were observed in orang-utans (plantigrade type; on the order of 370), the median number in white-handed gibbons (plantigrade type; on the order of 650) and the maximum number in cats (digitigrade type; on the order of 1,100). Figure 4 shows a comparison of the number of muscle fibers per unit area according to 


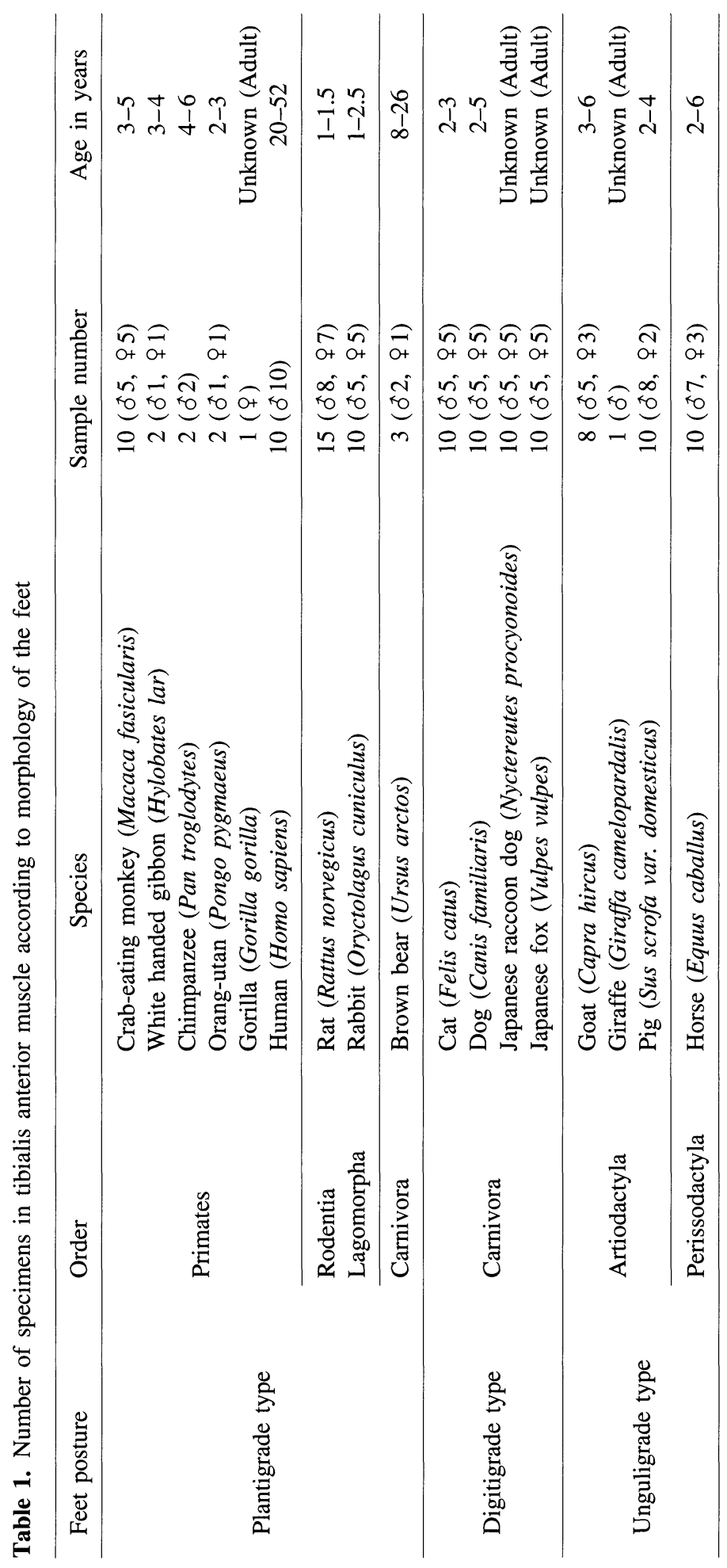



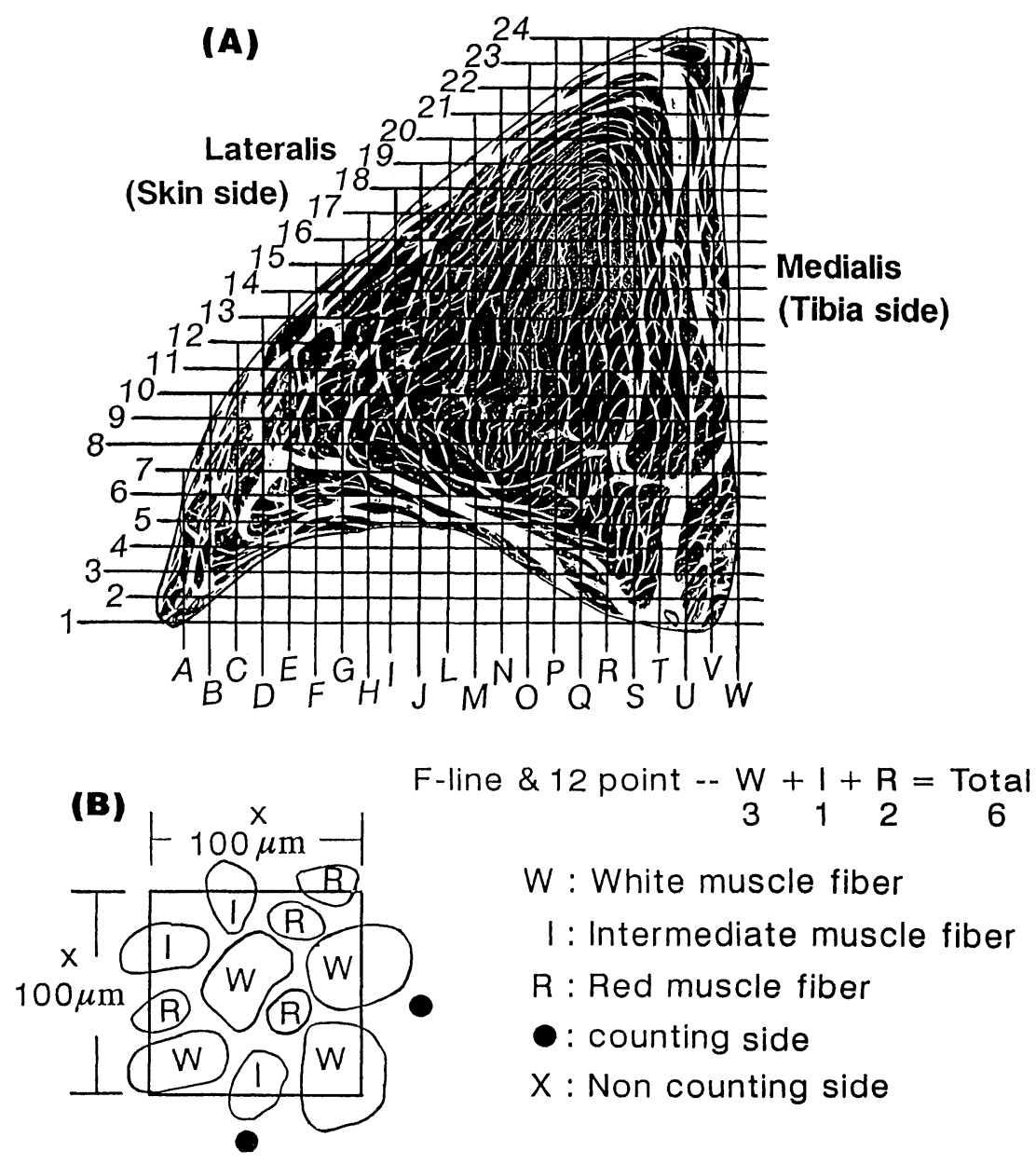

Fig. 1. A: Cross-section of the venter of the human anterior tibial muscle. B: The method of scanning muscle fibers with a micrometer.

the morphology of the feet. Out of 17 species of 6 orders, the number of the muscle fibers was largest in species of the digitigrade type (cats, foxes, dogs, and Japanese raccoon dogs). Median values were seen in the unguligrade type (pigs, giraffe, goats, and horses) and some species of the plantigrade type (rabbits and white-handed gibbons). In contrast, the number of muscle fibers was small in the plantigrade type, including humans, crab-eating monkeys, chimpanzees, gorilla, rats, brown bears, and orang-utans.

3) Frequencies of muscle fiber types according to the morphology of the feet

The frequencies of muscle fiber types were calculated according to the morphology of the feet, and the average are shown in Fig. 5. The plantigrade type was further 


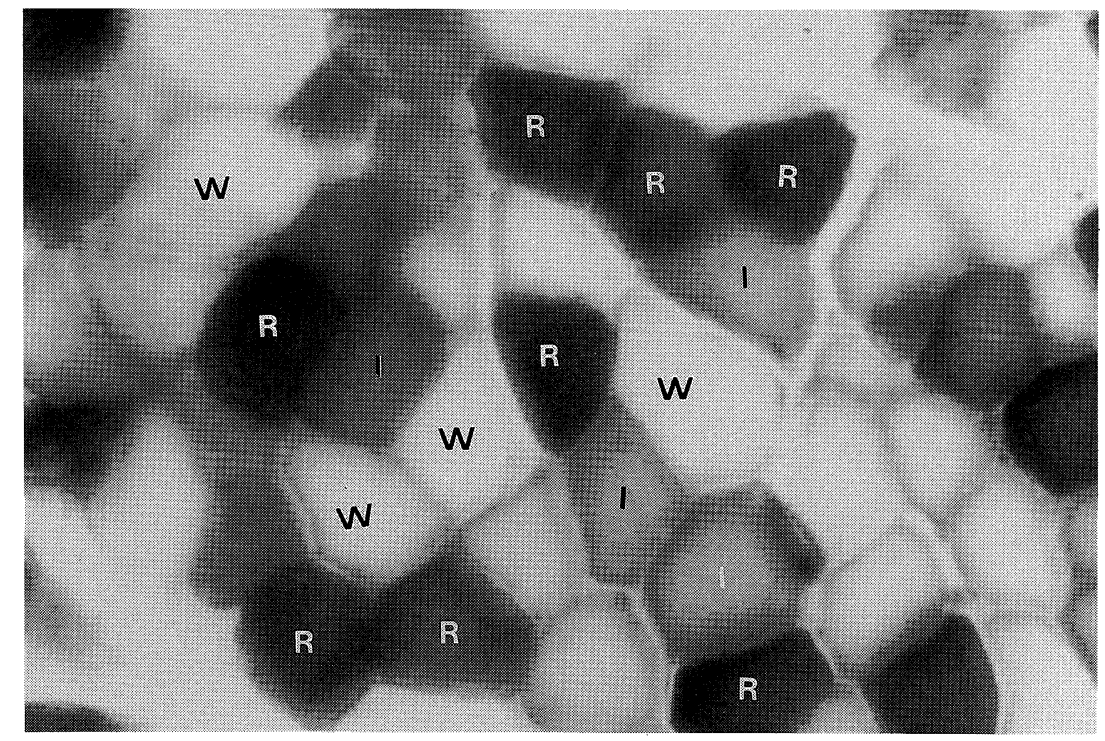

Fig. 2. Muscle fiber type of the human anterior tibial muscle observed by Sudan black B. $(\times 200)$ R: Red muscle fiber; I: Intermediate muscle fiber; W: White muscle fiber

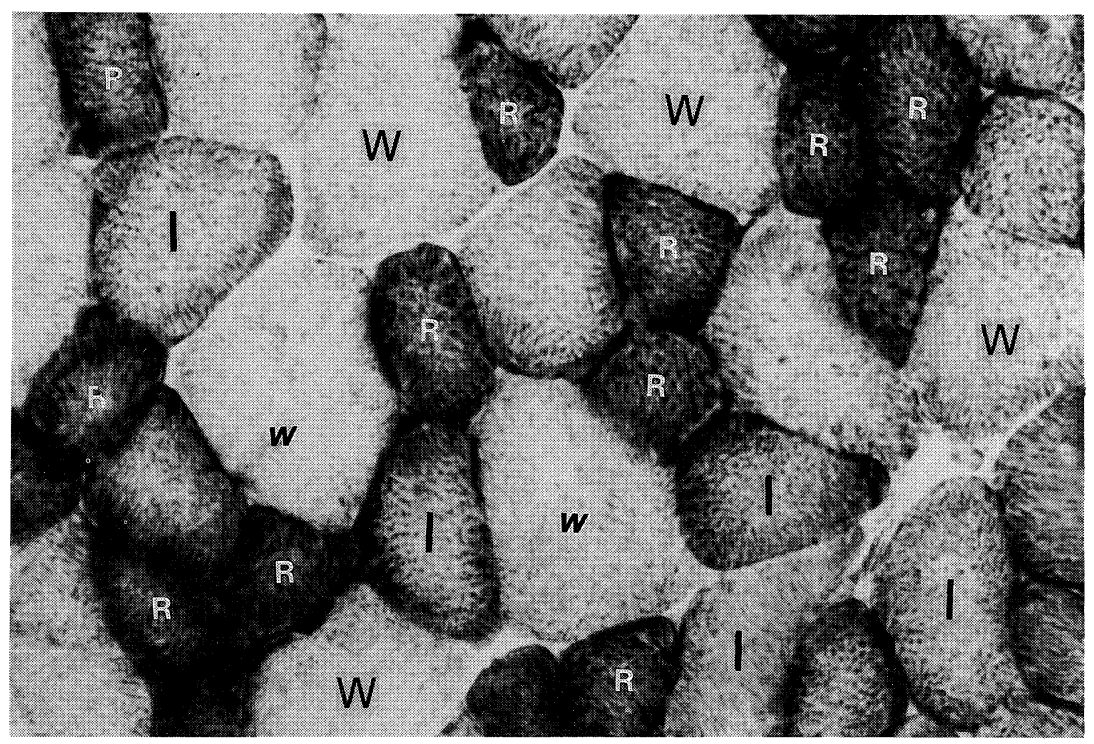

Fig. 3. Muscle fiber types of the rat anterior tibial muscle observed by succinic dehydrogenase. $(\times 200)$ For abbrevation, see Fig. 1 . 


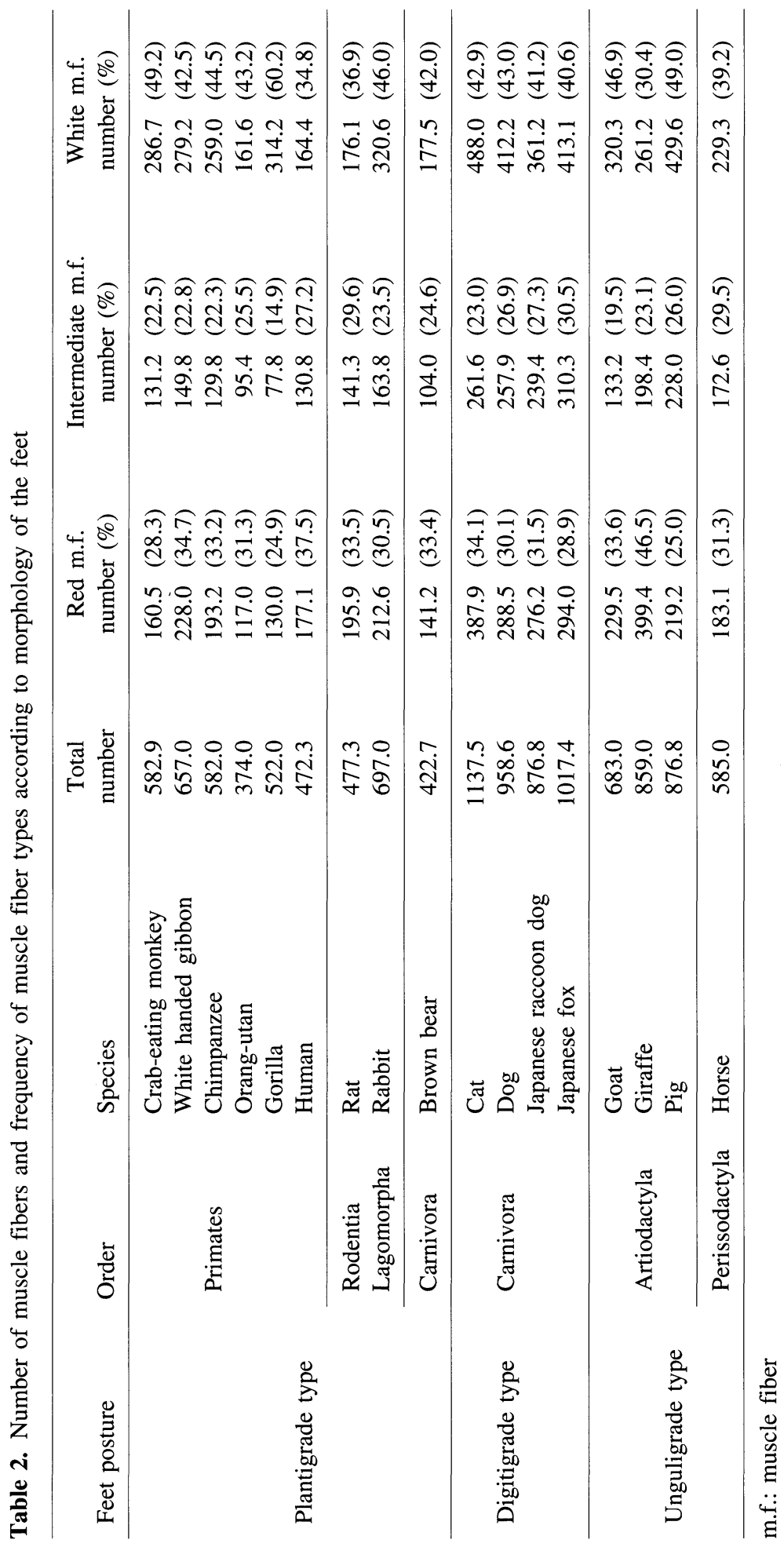




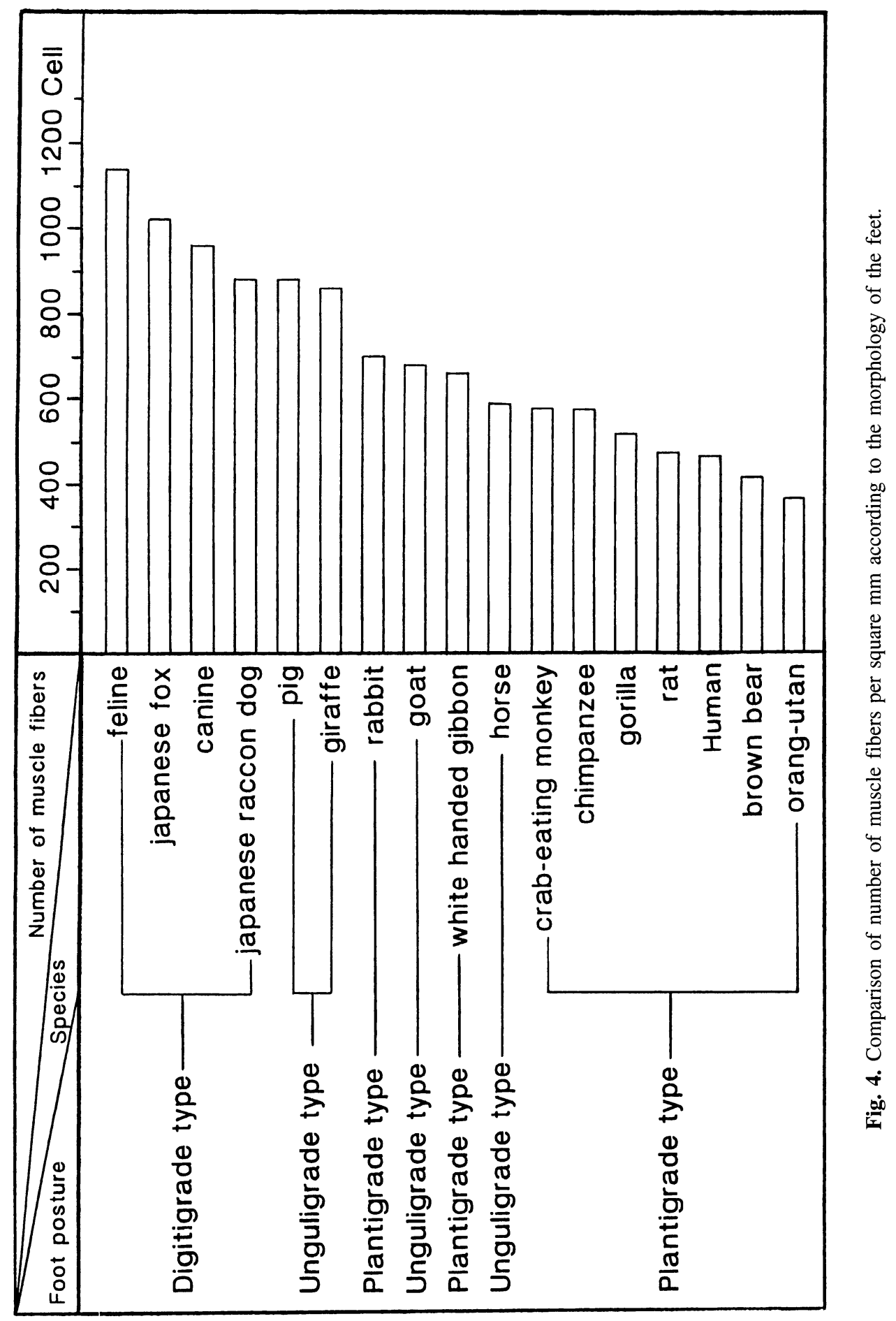




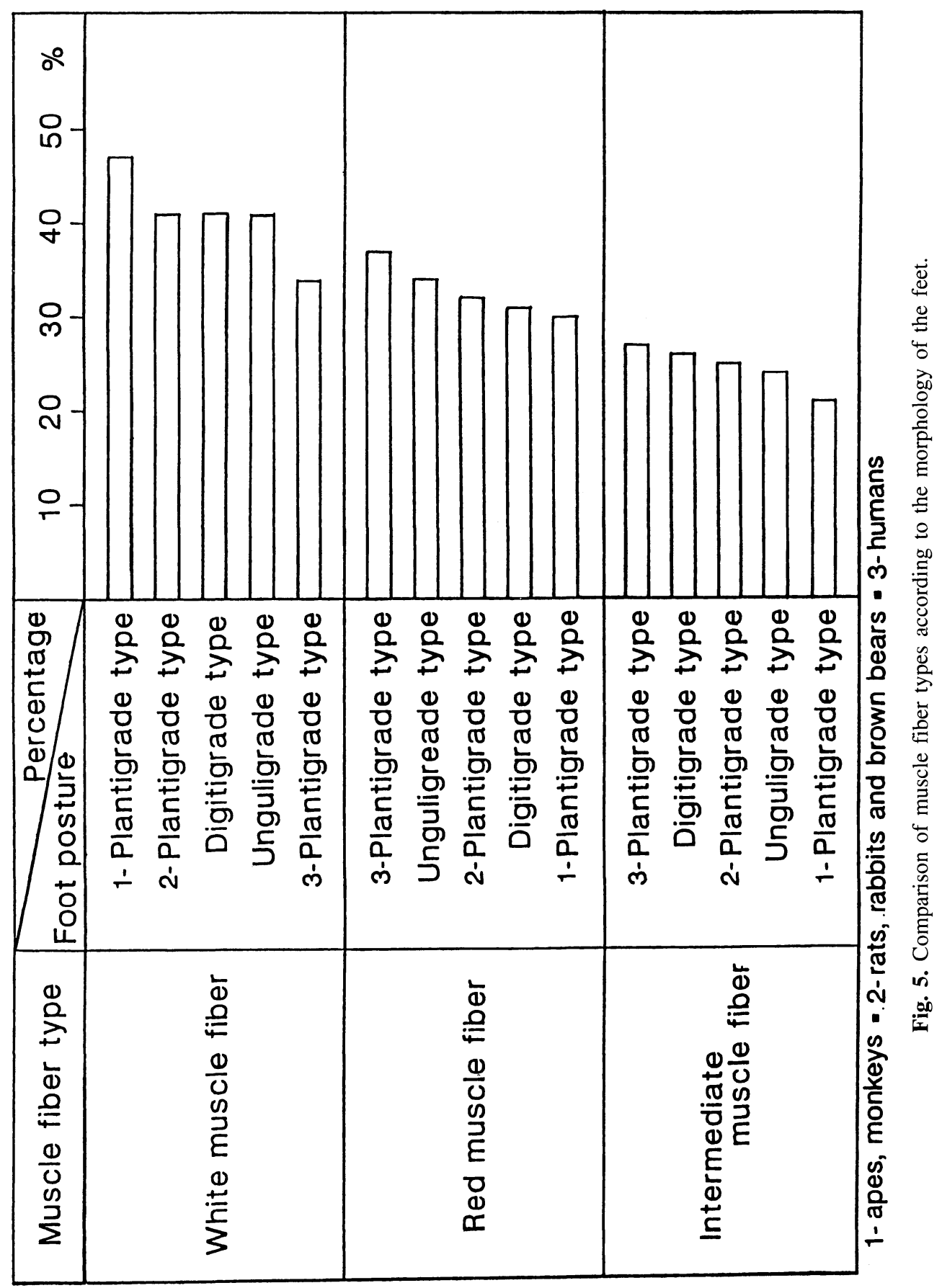


divided into three groups: human and apes, monkeys and rats, rabbits and bears. The white muscle fibers were most frequently seen in plantigrade apes and monkeys (47.9\%), followed by rats, rabbits and brown bears, also of the plantigrade type (41.6\%), the digitigrade type (41.9\%), and the unguligrade type (41.4\%). The frequencies in these three groups were all on the order of $41 \%$, and thus, no significant differences were observed among these groups. The lowest frequency was seen in humans (plantigrade type $34.8 \%$ ). With respect to red muscle fibers, humans (plantigrade type) showed the highest value $(37.5 \%)$, followed by the unguligrade type $(34.1 \%)$, plantigrade type excluding primates $(32.5 \%)$ and digitigrade type $(31.2 \%)$. The value was lowest in apes and monkeys (plantigrade type, $26.7 \%$ ). The frequency of intermediate muscle fibers was highest in humans $(27.7 \%)$, followed by the digitigrade type $(26.9 \%)$, plantigrade type excluding primates $(25.9 \%)$, and unguligrade type $(24.5 \%)$. The lowest value was seen in apes and monkeys (plantigrade type, $21.6 \%$ ), similar to the findings in red muscle fibers.

When the frequencies of muscle fiber types per unit area were compared among the species, the frequencies of red and white muscle fibers were in good balance (about 30\%) in humans and rats (plantigrade type). In foxes (digitigrade type), the frequency of intermediate muscle fibers $(30.5 \%)$ was higher than that of red muscle fibers $(28.9 \%)$. White muscle fibers were most frequently seen in gorilla (plantigrade type, $60.2 \%$ ). Red muscle fibers were most frequently seen in giraffe (unguligrade type, $46.5 \%$ ). In other species, the average of white muscle fibers was about $44 \%$, followed by $31 \%$ for red muscle fibers and $24 \%$ for intermediate muscle fibers. Thus, white muscle fibers were observed frequently.

\section{DISCUSSION}

The feet of mammals basically consist of seven tarsal bones, five metatarsal bones, and five phalanges including proximal, middle and distal phalanges, as seen in the feet of humans. In mammals other than humans, however, the tarsal bones, metatarsal bones and some of the phalanges are sometimes adhered to each other, due to different biological mechanisms and locomotion systems, resulting different numbers of basic bones comprising the feet. As forms of adaptive radiation adequate for particular functions, morphology of the feet is divided into three types: plantigrade type, digitigrade type and unguligrade type (Fig. 6). Anatomically speaking, the phalanges, metatarsal bones and tarsal bones all touch the ground, and the entire planter is used for walking and running in the plantigrade type. In the digitigrade and unguligrade types, on the other hand, only the phalanges touch the ground, while the metatarsal and tarsal bones do not. Accordingly, the phalanges alone are used for walking and running. Thus, there are substantial differences from the plantigrade type.

With respect to the shape of the nails that protect the tips of fingers and distal bones of the phalanges, primates of the plantigrade type, including humans, have 


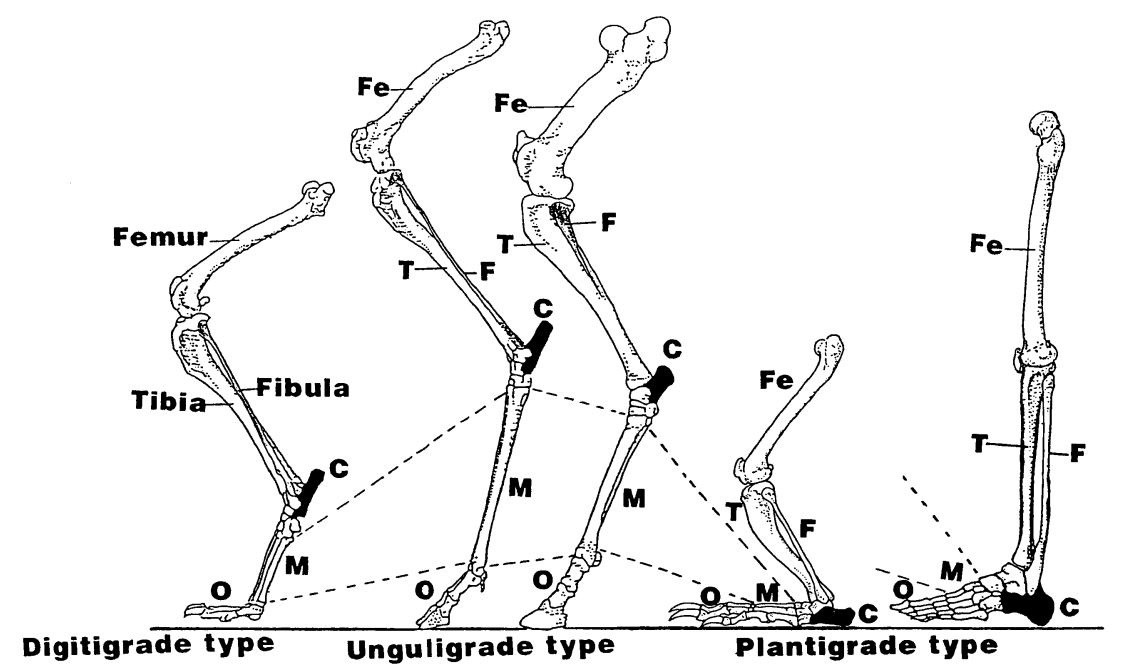

Fig. 6. Pattern of morphology of the feet in mammals. O: Ossa digitorum pedis; M: metatarsal bone; C: Calcaneus; F: Fibula; Fe: Femur; T: Tibia

flat nails, white rats and rabbits of rodentia and bears of carnivora (plantigrade type) have claws, as do dogs and cats (digitigrade type). In artiodactyla and perissodactyla (unguligrade type), the nail developed as locomotor organ (Dyce et al., 1987). Because the contact area of the planter is large in the plantigrade type except in humans, the feet are not suited to walk and run a long distance. On the other hand, they are appropriate for slow and forceful actions like those used in climbing. In contrast, rebound from the ground is focused on the phalanges in the digitigrade and unguligrade types. Because the metatarsal and tarsal bones are nearly vertical, however, the rebound from the ground can be dispersed due to the bending and stretching of the ankle joints. Accordingly, the feet of these types are suited for running.

In the unguligrade type, the tips of the phalanges are differentiated into the hoof. Accordingly, rebound from the ground is absorbed and dispersed by the hoof. At the same time, the hoof, which consists of scleroprotein, has an adiabatic effect. Moreover, since the metatarsal bones are longer than those of the digitigrade type, the stride is large and the feet are suited to running and walking a long distance. These considerations are in line with the study of Garland (1983), who found in most of the references a clear relationships between the body mass and the maximum running speed in the mammals of 106 species in 9 orders; among them, as against the slower running speed of the primates and rodentia (platigrade type), the carnivora (digitigrade type) and artiodactyla as well as the perissodactyla (unguligrade type) have very good ability for fast running. 
With respect to the function of the feet, humans demonstrate the walking pattern of the plantigrade type (Fig. 7-A), like bears, rats, and monkeys, but while running, the pattern changes to that of the digitigrade type (Fig. 7-B), like dogs and cats, in which only the phalanges are used. Thus, the human locomotion system is the most specially differentiated in terms of function. In light of these observations, humans may be considered to be suited to running. According to Baba (1990), however, the morphology of the human lower limbs is different from that of the digitigrade and unguligrade types, which are accustomed to running fast, and therefore, humans are better suited to walking fast, not running. At any rate, the skeletal system of the feet of the plantigrade, digitigrade, and unguligrade types are basically the homology (Dyce et al., 1987).
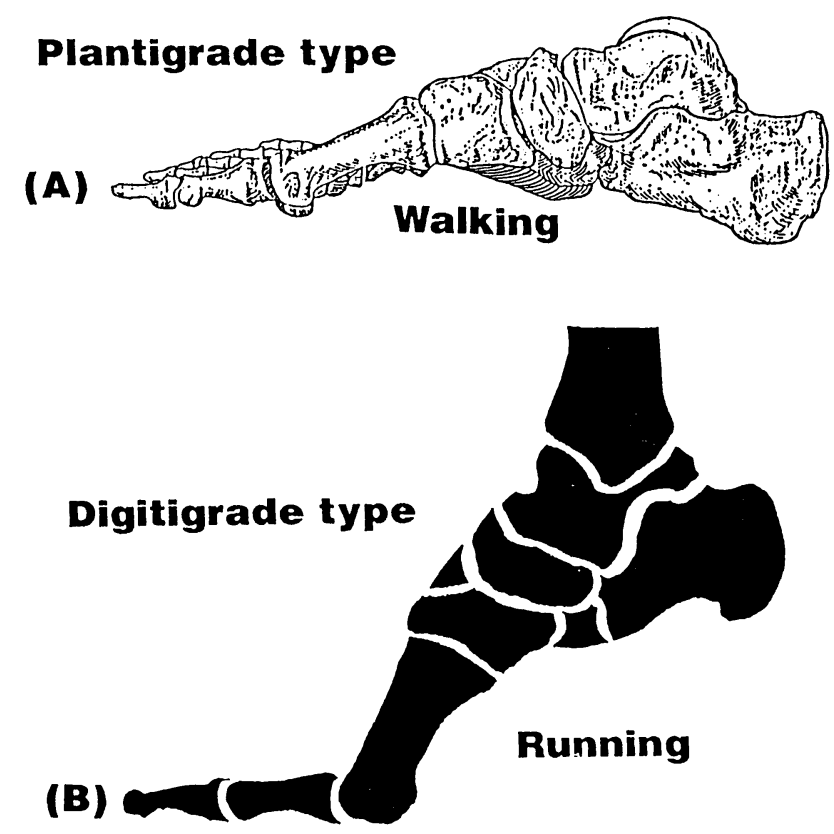

Fig. 7. Functional and morphological changes of the foot in human locomotion.

The skeletal muscles that control the feet include the extensor group in the anterior part of the crus, flexor group in the posterior part, and fibular muscles on the lateral side. The anterior tibial muscle of the anterior side participate in the dorsiflexion of the ankle joints and are responsible for walking and running together with the plantar flexors on the posterior side. Many studies have demonstrated the function and morphology of the anterior tibial muscle (Alder et al., 1958; Hollinshead, 1960; Miller et al., 1964; Crouch, 1969; Yellin and Guth, 1970; Tauchi et al., 1971; Kimura et al., 1978, 1979, 1982; Updike, 1984; Kimura, 1990). When the number 
of muscle fibers comprising the anterior tibial muscle was compared according to the morphology of the feet, the number was found to be the largest in the digitigrade type, followed by the unguligrade type and smallest in the plantigrade type. From the functional point of view, the number of muscle fibers indicates the size of the muscle fibers. In other words, the muscle fibers are thick and thus, the number of muscle fibers in a unit area of $1 \mathrm{~mm}^{2}$ is small in the plantigrade type, including primates, rodentia, and bears of carnivora, which exhibit slow and forceful activity. In canidae and felidae (digitigrade type), which are suited to rapid action, the muscle fibers are thin, and the number of muscle fibers per unit area is large. In contrast, these values are intermediate in artiodactyla and perissodactyla of the unguligrade type (Kimura, 1993).

These findings suggest that the large number of muscle fibers is advantageous for fast action while thick muscle fibers are best suited to slow actions that require muscle force. This findings is supported by studies reporting that muscle fibers with strong contraction force are thick, while those that produce small, weak contractions are thick (Bowden and Goter, 1960; Aherne et al., 1971). Given, however, the fact that observation in this study is limited to the anterior tibial muscle, the possibility cannot be excluded that the above differences merely represent phylogenetic features unrelated with the foot morphology. Frequencies of the red muscle fibers with slow contraction, intermediate muscle fibers with plastic contraction, and white muscle fibers with fast contraction, in particular, are reported to be closely correlated with the locomotion of various mammals (Hall-Craggs, 1975; Kimura and Inokuchi, 1985). Similarly, when the muscle fiber types are compared according to the morphology of the feet, the frequency of white muscle fibers with strong instantaneous response is high in apes and monkeys, rats, rabbits and bears (plantigrade type), while the frequencies of red and intermediate muscle fibers are high in humans, who are also classified as the plantigrrade type. This difference within the plantigrade type is thought to be attributable to different locomotion systems, i.e., between the quadrupedal walking of animals and the continuous erect biperdalism of humans. While the frequency of red muscle fibers with sustaining power is frequently observed in the unguligrade type, the frequencies of white and intermediate muscle fibers are observed to be high in the digitigrade type and thus, the feet are appropriate for fast running.

\section{ACKNOWLEDGEMENTS}

The author thank Professor Morihiko Okada (Institute of Health and Sport Sciences University of Tsukuba) for his help during the preparation of the manuscript.

\section{REFERENCES}

Aherne, W., Ayyar, D.R., Clarke, P.A. (1971) Muscle fiber size in normal infants, children and 
adolescents; An autopsy. J. Neural. Sci. 14, 171-182.

Alder, A.B., Grawfod, G.N.C., and Edwards, R.G. (1958) The growth of the muscle tibialis anterior in the normal rabbit in relation to the tension-length ratio. Proc. Roy. Soc., B. 148, 207-216.

Baba, H. (1990) Foot in mammals, primates and humans: A functional-morphological overview. $J$. Anthrop. Soc. Nippon 98, 65-74. (In Japanese with English summary)

Barnard, R.J., Edgerton, V.R., Furukawa, T., and Peter, J.B. (1971) Histochemical, biochemical and contractile properties of red, white and intermediate fibers. Am. J. Physiol. 220, 410-414.

Bowden, D.H., and Goyer, R.A. (1960) The size of muscle fibers in infants and children. Am. A. Arch. Pathol. 69, 188-198.

Cruoch, J.E. (1969) Text-Atlas of Cat Anatomy, Lea \& Febiger, Philadelphia.

Dubowitz, V., and Pearse, A.G.E. (1960) A comparative histochemical study of oxidative and phosphorylase activity in skeletal muscle. Histochemie 2, 105-117.

Denny-Brown, D. (1929) The historical features of striped muscle in relation to its functional activity. Proc. Roy. Soc. B 104, 371-411.

Dyce, K.M., Sack, W.O., and Wensing, C.J.G. (1987) Textbook of Veterinary Anatomy, W.B. Saunders, Philadelphia.

Edgerton, V., and Simpson, D.R. (1969) The intermediate muscle fiber of rats and guinea-pigs. $J$. Histochem. Cytochem. 17(12), 828-838.

Garland, H., Jr. (1983) The relation between maximal running speed and body mass in terrestrial mammals. J. Zool., Lond. 199, 157-170.

Hall-Craggs, E.C.B. (1975) Physiological and histochemical parameters in comparative locomotor studies. In Prosimian Biology (Martin, D.D., Doyle, G.A., and Malker, A.C., ed.), Duckworth, London, pp. 829-845.

Hildebrand, M. (1982) Analysis of Vertebrate Structure, John Wiley \& Sons, New York.

Hollinshead, W.H. (1960) Functional Anatomy of the Limbs and Back, 2nd Ed., W.B. Saunders, Philadelphia \& London.

Kimura, T. (1990) Muscle fiber type in primates. In Primatology Today (Ehara, A., Kimura, T., Takenaka, O., and Iwamoto, M., ed.), Elsevier Science Publishers, Amsterdam, pp. 481-482.

Kimura, T. (1993) Correlation between feet posture and muscle fiber size in mammals-comparison of the anterior tibial muscle fiber among Plantigrade type, Digitigrade type and Unguligrade type. Acta Anat. Nippon 68, 617-625. (In Japanese)

Kimura, T., Ajri, T., Ihara, K., and Inokuchi, S. (1978) The effects of running exercise on the myofibrous organization of M. tibialis anterior in adult rats. J. Showa Med. Assoc. 38, 525-532. (In Japanese)

Kimura, T., Ito, R., Sato, T., and Sato, I. (1979) Myofibrous organization of M. tibialia anterior in crab-eating monkey. J. Showa Med. Assoc. 39, 381-388. (In Japanese)

Kimura, T., Ochiai, H., Jinnai, T., and Kaneuti, Y. (1982) Morphological changer of the muscle fibers of the denervated tibialis anterior muscle of rats. J. Showa Med. Assoc. 42, 503-510. (In Japanese)

Kimura, T., and Inokuchi, S. (1985) Distribution pattern of muscle fiber type in musculus biceps brachii of white-handed gibbon. J. Anthrop. Soc. Nippon 93, 371-380.

Miller, M.E., Christensen, G.C., and Evans, H.E. (1964) An Anatomy of the Dog, W.B. Saunders, Philadelphia, pp.152-162.

Nachlas, M.M., Tsou, K.C., Desouza, E., Change, C.S., and Seligman, A.M. (1957) Cytochemical demonstration of succinic dehydrogenase by the use of a new P-Nitropheny substituted ditetrazole. J. Histochem. 5, 420-436.

Ogata, T. (1958) A histochemical study of the red and white muscle fibers. Part 1. Activity of the 
succinoxidase system in muscle fibers. Acta Med. Okayama 12, 216-227.

Padykura H.A., and Herman, E. (1955) The specificity of the histochemical method for adenosin triphosphatase. J. Histochem. Cytochem. 3, 170-195.

Romanul, F.C.A. (1964) Enzymes in muscle. I. Histochemical studies on enzymes in individual muscle fibers. Arch. Neurol. 11, 355-368.

Stein, J.M., and Padykura, H.A. (1962) Histochemical classification of individual skeletal muscle fibers of the rat. Am. J. Anat. 110, 103-123.

Tauti, H., Yoshioka, T., and Kobayashi, H. (1971) Age change of skeletal muscle in rats. Gerontologia 17, 219-227.

Updike, S.T. (1984) Anatomy of the tarsal tendons of the equine tibialis cranialis and peroneus tertius muscle. Am. J. Vet. Res. 45, 1379-1382.

Yellin, H., and Guth, L. (1970) The histochemical classification of muscle fibers. Exp. Neurol. 26, 424-432. 